\title{
Nicotinic Acetylcholine Receptors Mediate the Suppressive Effect of an Injection of Diluted Bee Venom into the GV3 Acupoint on Oxaliplatin- Induced Neuropathic Cold Allodynia in Rats
}

\author{
Heera Yoon, ${ }^{a}$ Min Joon Kim, ${ }^{b}$ Insoo Yoon, ${ }^{a}$ Dong Xing Li, ${ }^{a}$ Hyunsu Bae, ${ }^{a}$ and \\ Sun Kwang Kim*, ${ }^{*}, b$ \\ ${ }^{a}$ Department of Physiology, College of Korean Medicine, Kyung Hee University; Seoul 130-701, Republic of \\ Korea: and ${ }^{b}$ Department of East-West Medicine, Graduate School, Kyung Hee University; Seoul 130-701, Republic of \\ Korea. \\ Received November 18, 2014; accepted February 24, 2015; advance publication released online March 5, 2015
}

Oxaliplatin, a platinum-based chemotherapy drug, often induces acute neuropathic pain, especially cold allodynia, even after a single administration. Subcutaneous injection of diluted bee venom (BV) into acupoints has been used to treat various pain symptoms in traditional oriental medicine. Although we previously demonstrated the suppressive effect of BV injection on oxaliplatin-induced cold allodynia in rats, its neurochemical mechanism remained unclear. This study investigates whether and how the cholinergic system mediates the relieving effect of $\mathrm{BV}$ injection on cold allodynia in oxaliplatin-administered rats. The behavioral signs of cold allodynia induced by an oxaliplatin administration $(6 \mathrm{mg} / \mathrm{kg}$, intraperitoneally (i.p.)) were evaluated by a tail immersion test in cold water $\left(4^{\circ} \mathrm{C}\right) . \mathrm{BV}(0.25 \mathrm{mg} / \mathrm{kg}$, subcutaneously (s.c.)) injection into the Yaoyangguan acupoint, located between the spinous processes of the fourth and fifth lumbar vertebrae, significantly alleviated the cold allodynia. This relieving effect of $\mathrm{BV}$ injection on oxaliplatin-induced cold allodynia was blocked by a pretreatment with mecamylamine (a non-selective nicotinic receptor antagonist, $2 \mathrm{mg} / \mathrm{kg}$, i.p.), but not by atropine (a non-selective muscarinic receptor antagonist, $1 \mathrm{mg} / \mathrm{kg}$, i.p.). Further, dihydro- $\beta$-erythroidinehydrobromide $(\mathrm{DH} \beta \mathrm{E}$, an $\alpha 4 \beta 2$ nicotinic antagonist, $5 \mathrm{mg} / \mathrm{kg}$, i.p.) prevented the antiallodynic effect of $\mathrm{BV}$, whereas methyllycaconitine (an $\alpha 7$ nicotinic antagonist, $6 \mathrm{mg} / \mathrm{kg}$, i.p.) did not. Finally, intrathecal administration of $\mathrm{DH} \beta \mathrm{E}(10 \mathrm{~nm})$ blocked the $\mathrm{BV}$-induced anti-allodynic effect. These results suggest that nicotinic acetylcholine receptors, especially spinal $\alpha 4 \beta 2$ receptors, but not muscarinic receptors, mediate the suppressive effect of BV injection on oxaliplatin-induced acute cold allodynia in rats.

Key words oxaliplatin; bee venom; cholinergic; cold allodynia; nicotinic receptor; rat

Oxaliplatin is a third-generation platinum-based chemotherapy drug for advanced colorectal cancer. ${ }^{1)}$ Unlike the other platinum compounds (e.g. cisplatin and carboplatin), oxaliplatin does not induce nephrotoxicity and hepatotoxicity, but often induces a very acute painful neuropathy soon after an administration. ${ }^{2)}$ This acute neuropathy is the only major dose-limiting toxicity associated with oxaliplatin use $\mathrm{e}^{3)}$ and is characterized by the rapid onset of cold-induced peripheral dysesthesia, paresthesia, or hypoesthesia of the hands, feet, or throat. ${ }^{4,5)}$ Previous animal studies also have shown that a single administration of oxaliplatin $(6 \mathrm{mg} / \mathrm{kg}$, intraperitoneally (i.p.)) reproduces the neurotoxic profile, especially cold allodynia. ${ }^{6,7)}$ However, its mechanism is still unclear and an effective treatment of established neuropathic cold allodynia remains to be found. ${ }^{8)}$

A subcutaneous injection of diluted bee venom (BV) into acupoints, so called 'bee venom acupuncture,' has been used as a part of traditional oriental medicine to relieve pain and treat various diseases, such as arthritis, rheumatism, cancer, asthma and skin diseases. ${ }^{9-11)}$ It is a kind of peripheral nerve stimulation $^{12)}$ as similar to electroacupuncture (EA), but with the different method of stimulus (chemical vs. electrical). Thus, the analgesic mechanisms of BV injection are somewhat different from those of EA, although both therapeutic largely share the neurochemical pathway for the activation of the endogenous analgesic system. EA-induced analgesia is mediated by the endogenous opioid and/or the non-opioid analgesic system, such as the central noradrenergic, cholinergic, serotonergic and $\gamma$-aminobutyrate (GABAergic) pain inhibitory pathways. ${ }^{13)}$ In contrast, the analgesic effects of BV injection are reported to be mainly mediated by the central noradrenergic system, but not by the endogenous opioids. ${ }^{14,15)}$ In a rat model of oxaliplatin-induced neuropathic pain, we recently demonstrated that EA significantly relieves acute cold allodynia via the release of the endogenous opioids, but not via the activation of the noradrenergic system. ${ }^{16)}$ In the same rat model, interestingly, the anti-allodynic effect of BV injection is only partially mediated by the noradrenergic system, not by the opioids, ${ }^{17)}$ suggesting that the other non-opioid analgesic mechanism might play an important role in mediating the BV effect on oxaliplatin-induced cold allodynia.

Cholinergic modulation is one of the pharmacological methods to the treatment of pain. ${ }^{18)}$ Acetylcholine receptors are present in the spinal cord dorsal horn, in which nociceptive processing occurs. They are classified into two distinct receptors, nicotinic and muscarinic acetylcholine receptors, and the activation of spinal nicotinic or muscarinic receptors is known to produce analgesia. ${ }^{18,19)}$ Although our previous study ${ }^{20)}$ showed that spinal muscarinic, but not nicotinic, receptors mediate the anti-allodynic effect of EA in nerve-injured rats, a cholinergic mechanism for BV-induced analgesia has not yet been studied. In the present study, we examined if and how the cholinergic system plays a role in the relieving effects of $\mathrm{BV}$ injection on acute cold allodynia in oxaliplatin-adminis- 
(a)

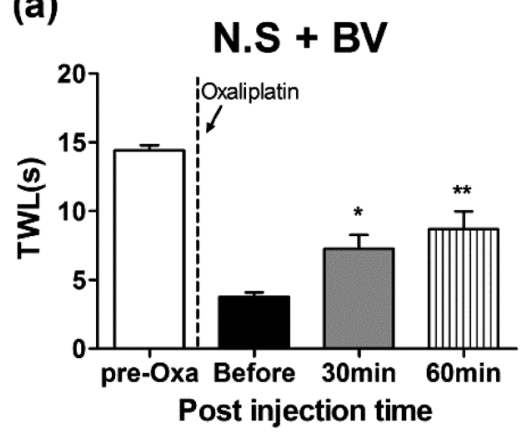

(b)

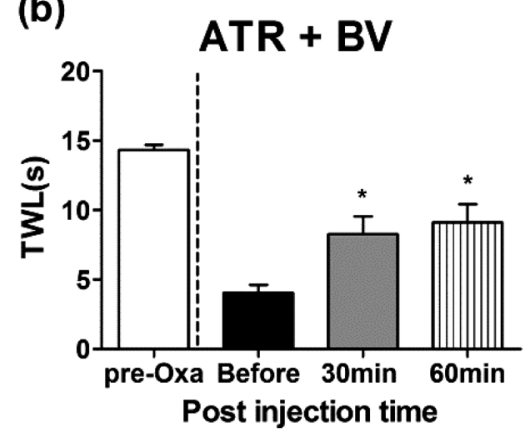

(c)

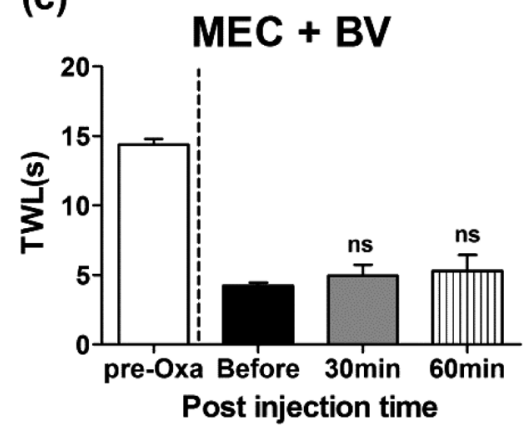

Fig. 1. The Effects of Non-selective Nicotinic and Muscarinic Receptor Antagonists on BV-Induced Analgesic Action on Oxaliplatin-Induced Cold Allodynia in Rats

The behavioral tests for cold allodynia were performed prior to an oxaliplatin injection ("pre-Oxa"), before an i.p. adminstration of the antagonists ("Before"), 30 min after BV $(0.25 \mathrm{mg} / \mathrm{kg}$, s.c.) treatment at Yaoyangguan (GV3) acupoint and one hour after BV treatment. (a) N.S+BV (normal saline+BV, $n=11)$, (b) ATR $+\mathrm{BV}$ (atropine $1 \mathrm{mg} / \mathrm{kg}+\mathrm{BV}, n=8$ ), (c) MEC+BV (mecamylamine $2 \mathrm{mg} / \mathrm{kg}+\mathrm{BV}, n=8$ ). Data are presented as mean \pm S.E.M. * $p<0.05$; $* * p<0.01$; ns: no significant, $v s$. "Before" by oneway repeated measures ANOVA followed by Dunnett's multiple comparison test.

tered rats.

\section{MATERIALS AND METHODS}

Animals Young adult male Sprague-Dawley rats (average $200 \mathrm{~g}$, 7 weeks old) (Daehan Biolink, Chungbuk, Korea) were housed in cages (3-4 rats per cage) with water and food available ad libitum. The room was maintained with a $12 \mathrm{~h} \mathrm{light/dark} \mathrm{cycle} \mathrm{(a} \mathrm{light} \mathrm{cycle;} \mathrm{08:00-20:00,} \mathrm{a} \mathrm{dark}$ cycle; 20:00-08:00) and kept at $23 \pm 2{ }^{\circ} \mathrm{C}$. All animals were acclimated in their cages for 1week prior to any experiments. All of the procedures were approved by the Institutional Animal Care and Use Committee of Kyung Hee University (KHUASP(SE)-14-010) and were conducted in accordance with the guidelines of the International Association for the Study of Pain. ${ }^{21)}$

Oxaliplatin Administration Oxaliplatin was obtained from Sigma Chemical Co., U.S.A. As described previously, ${ }^{6,22)}$ oxaliplatin was dissolved in a $5 \%$ glucose solution at a concentration of $2 \mathrm{mg} / \mathrm{mL}$ and was intraperitoneally administered at $6 \mathrm{mg} / \mathrm{kg}$.

Behavioral Test Cold allodynia induced by an oxaliplatin administration was assessed in rats by using the tail immersion test in a water bath maintained at $4^{\circ} \mathrm{C}$. Each rat was lightly immobilized in a plastic holder and its tail was drooped for proper application of cold water stimuli. The rats were adapted to the holder for $2 \mathrm{~d}$ before starting behavioral tests. After the tail was immersed in $4^{\circ} \mathrm{C}$ water, the tail withdrawal latency (TWL) to an abrupt tail movement was measured with a cut-off time of $15 \mathrm{~s}$. The tail immersion test was repeated five times at $5 \mathrm{~min}$ intervals. When calculating the average TWL, the cutoff time was assigned to normal responses. The average TWL was taken as a measure of the severity of cold allodynia; a shorter TWL was interpreted as more severe allodynia.

Treatment of Antagonists and BV Injection BV from Apis mellifera was purchased from Sigma (V3375) and was dissolved in normal saline (N.S) to a concentration of $0.025 \mathrm{mg} / \mathrm{mL}$. BV is known to contain many active components, including peptides (e.g. melittin and apamine), enzymes (e.g. phospholipase A2) and small molecules (e.g. histamine).

To investigate the cholinergic mechanism of BV-induced analgesia, oxaliplatin-administered rats were randomly divid- ed into three groups: N.S+BV, atropine (ATR)+BV, and mecamylamine hydrochloride (MEC) $+\mathrm{BV}$. After a baseline cold sensitivity (TWL) was measured, ATR+BV and $\mathrm{MEC}+\mathrm{BV}$ groups were treated intraperitoneally with ATR (non-selective muscarinic receptor antagonist, $1 \mathrm{mg} / \mathrm{kg}$, Sigma) and MEC (non-selective nicotinic receptor antagonist, $2 \mathrm{mg} / \mathrm{kg}$, Sigma), respectively. N.S+BV group was treated intraperitoneally with normal saline. Thirty minutes later, BV $(0.25 \mathrm{mg} / \mathrm{kg})$ dissolved in N.S was injected subcutaneously into the Yaoyangguan (GV3) acupoint. This acupoint is located between the spinous processes of the fourth and the fifth lumbar vertebrae ${ }^{23)}$ and BV injection (1 mg/kg, subcutaneously (s.c.)) into the Yaoyanguan showed a greater anti-allodynic effect in oxaliplatinadministered rats than BV injection into the Quchi (LI11, located on forelimb) or Zusanli (ST36, located on hindlimb) acupoint. ${ }^{17)} \mathrm{We}$ confirmed such acupoint-specific effects at a low dose of BV $(0.25 \mathrm{mg} / \mathrm{kg}$, s.c.) used in this study (Supplemental Fig. 1). The tail immersion test was performed again $30 \mathrm{~min}$ and $1 \mathrm{~h}$ after BV injection.

To examine the nicotinic acetylcholine receptor mechanism of BV-induced anti-allodynia, methyllycaconitine citrate (MLA, selective $\alpha 7$ nicotinic receptor antagonist, $6 \mathrm{mg} / \mathrm{kg}$, Tocris) or dihydro- $\beta$-erythroidinehydrobromide $(\mathrm{DH} \beta \mathrm{E}$, selective $\alpha 4 \beta 2$ nicotinic receptor antagonist, $5 \mathrm{mg} / \mathrm{kg}$, Tocris) was administered intraperitoneally. To further confirm whether spinal $\alpha 4 \beta 2$ nicotinic receptors mediate the analgesic effect of BV injection, $\mathrm{DH} \beta \mathrm{E}(50 \mu \mathrm{L}$, dissolved in N.S at a concentration of $10 \mathrm{~nm}$ ) was administered intrathecally under isoflurane anesthesia as described previously. ${ }^{24)}$ The doses of antagonists were selected based on previously published studies that show selectivity for the individual receptor subtypes.

Statistical Analysis All data are presented as mean \pm standard error of the mean (S.E.M.). For statistical analysis, paired $t$-test or one-way repeated measures ANOVA followed by Dunnett's multiple comparison test was used. In all cases, $p<0.05$ was considered significant.

\section{RESULTS}

Effects of Non-selective Muscarinic and Nicotinic Receptor Antagonists on BV-Induced Anti-allodynia As shown in our previous study, ${ }^{16)}$ a significant sign of cold allodynia was induced from $3 \mathrm{~d}$ after a single oxaliplatin $(6 \mathrm{mg} / \mathrm{kg}$, i.p.) 
(a)

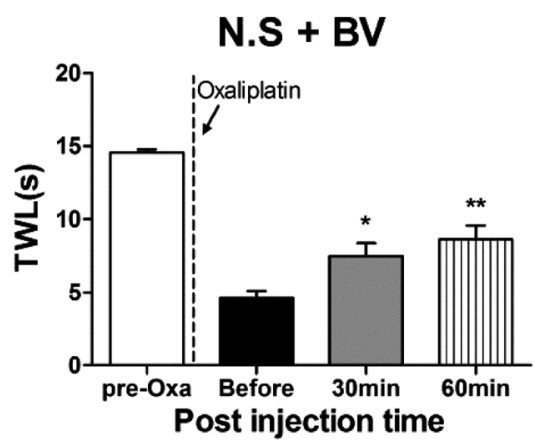

(b)

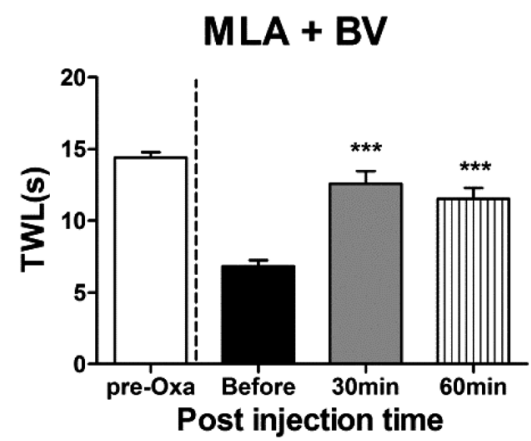

(c)

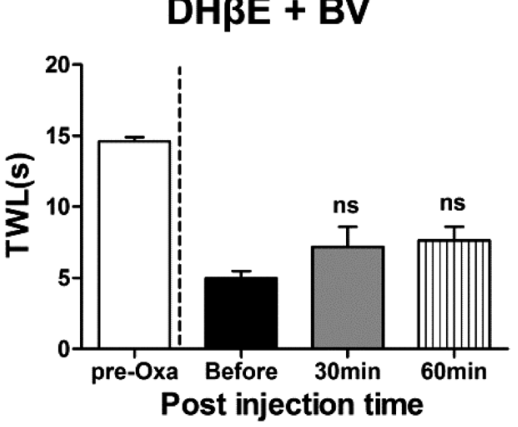

Fig. 2. The Effects of Nicotinic Receptor Subtype Antagonists on BV-Induced Anti-allodynic Action

The behavioral tests for cold allodynia were performed prior to an oxaliplatin injection ("pre-Oxa"), before an i.p. adminstration of the antagonists ("Before"), 30 min after BV $(0.25 \mathrm{mg} / \mathrm{kg}$, s.c.) treatment at Yaoyangguan (GV3) acupoint and one hour after BV treatment. (a) N.S+BV (normal saline+BV, $n=7$ ), (b) MLA+BV (methyllycaconitine $6 \mathrm{mg} / \mathrm{kg}+\mathrm{BV}, n=8$ ), (c) $\mathrm{DH} \beta \mathrm{E}+\mathrm{BV}$ (dihydro- $\beta$-erythroidinehydrobromide $5 \mathrm{mg} / \mathrm{kg}+\mathrm{BV}, n=6$ ). Data are presented as mean $\pm \mathrm{S}$.E.M. $* p<0.05, * * p<0.01$; $* * * p<0.001$; ns: no significant, $v s$. "Before" by one-way repeated measures ANOVA followed by Dunnett's multiple comparison test.

injection and lasted up to $7 \mathrm{~d}$ after an injection. Thus, we tested whether and how the cholinergic system meditates the relieving effect of BV injection on cold allodynia from 3 to $7 \mathrm{~d}$ after an oxaliplatin administration. Note that the TWLs measured prior to an oxaliplatin injection ("pre-Oxa") were nearly cut-off value (15s) and the TWLs measured 3 to $7 \mathrm{~d}$ after an oxaliplatin injection (before an administration of antagonists, "Before") were markedly decreased to about 5s (Figs. 1-3).

To see which acetylcholine receptors mediate the suppressive effect of BV injection on cold allodynia, we examined the effect of a non-selective muscarinic receptor antagonist ATR or a non-selective nicotinic antagonist MEC on BVA-induced anti-allodynia. Each of the antagonists alone had no significant effect on cold allodynia (Supplemental Fig. 2). In addition, no significant difference in TWL before and after N.S injection at GV3 ( $p>0.05)$ was observed (Supplemental Fig. 1). In the N.S+BV group, there was a significant increase in TWL after BV treatment $(p<0.05$, Fig. 1A). A systemic injection of ATR $(1 \mathrm{mg} / \mathrm{kg}$, i.p.) did not prevent the anti-allodynic effect of BV injection $(p<0.05$, Fig. 1B), whereas an injection of MEC $(2 \mathrm{mg} / \mathrm{kg}$, i.p.) markedly blocked the BV effect $(p>0.05$, Fig. 1C). This indicates that nicotinic acetylcholine receptors, but not muscarinic receptors, are involved in the relieving effect of BV injection on oxaliplatin-induced cold allodynia.

Effects of Nicotinic Receptor Subtype Antagonists on BV-Induced Anti-allodynia To determine which nicotinic receptor subtype plays a major role in mediating the anti-allodynic action of BV injection, selective antagonists against $\alpha 7$ and $\alpha 4 \beta 2$ nicotinic receptors were used. An i.p. pretreatment with N.S (Fig. 2A) or $\alpha 7$ nicotinic antagonist MLA (Fig. 2B) did not prevent the anti-allodynic effect of BV treatment $(p<0.05)$. In contrast, the relieving effect of $\mathrm{BV}$ injection on cold allodynia was blocked by an i.p. pretreatment with $\alpha 4 \beta 2$ nicotinic antagonist $\mathrm{DH} \beta \mathrm{E}(p>0.05$, Fig. 2C). We further showed that an intrathecal (i.t.) injection of $\mathrm{DH} \beta \mathrm{E}$ blocked the suppressive effect of BV injection on cold allodynia (Fig. 3B, $p>0.05$ ), but an i.t. injection of N.S did not (Fig. 3A, $p<0.001)$. This suggests that $\mathrm{BV}$ treatment alleviates cold allodynia in oxaliplatin-injected rats via the activation of spinal $\alpha 4 \beta 2$ nicotinic acetylcholine receptors. (a)

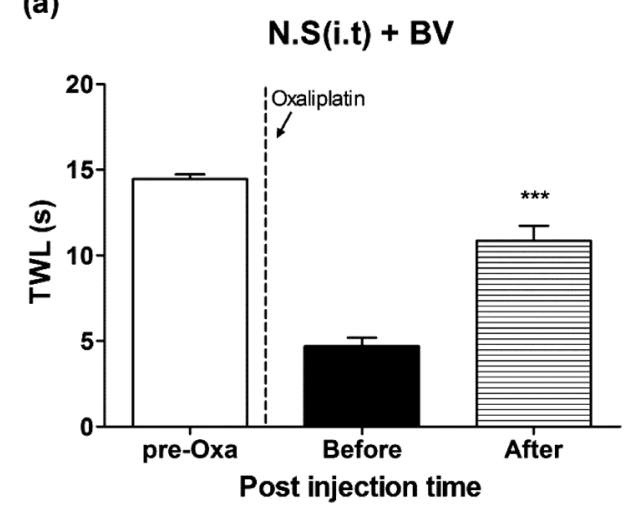

(b)

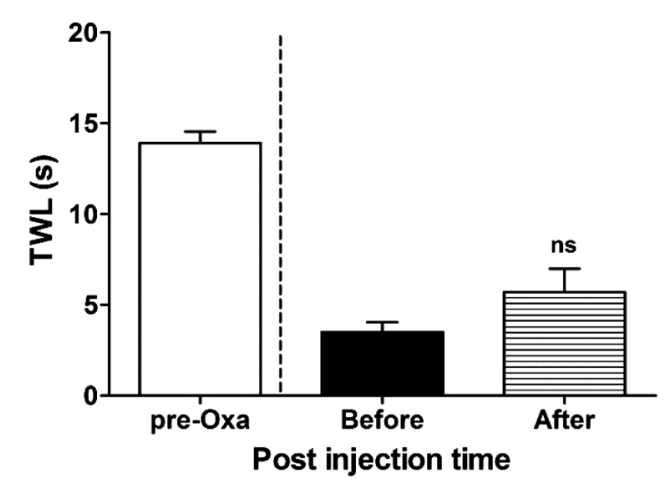

Fig. 3. The Effects of i.t. Injection of $\mathrm{DH} \beta \mathrm{E}$ on BV-Induced Antiallodynic Action

The behavioral tests for cold allodynia were performed prior to an oxaliplatin injection ("pre-Oxa"), before an injection of $\mathrm{DH} \beta \mathrm{E}$ (i.t.) ("Before") and after BV $(0.25 \mathrm{mg} / \mathrm{kg}$, s.c.) treatment at Yaoyangguan (GV3) acupoint. (a) N.S (i.t) $+\mathrm{BV}(n=8)$, (b) DH $\beta$ E (i.t.) $+\mathrm{BV}(n=5)$. Data are presented as mean \pm S.E.M. *** $p<0.001$; ns: no significant, vs. "Before" by paired $t$-test.

\section{DISCUSSION}

About $85 \%$ to $95 \%$ of oxaliplatin-treated patients rapidly develop pain without motor dysfunction during the oxaliplatin administration period, peaking at the first $24-48 \mathrm{~h}^{3,5)}$ There have been only a small number of reports showing the effective treatment of oxaliplatin-induced neuropathic pain. Thus, 
new therapeutic options for this pain are critically needed. In this regard, we recently showed that a subcutaneous injection of diluted BV into the GV3 acupoint markedly attenuates oxaliplatin-induced cold allodynia in rats with its effect lasting at least $2 \mathrm{~h},{ }^{17)}$ which is longer than the duration of morphine $(2 \mathrm{mg} / \mathrm{kg}$, i.p.) analgesia (ca. $\left.1 \mathrm{~h}) .{ }^{16}\right)$ This result suggests that BV injection could be a potential therapeutic option. However, the mechanisms of the anti-allodynic effect of BV injection is still unclear, because the BV effect was not blocked by an opioid antagonist, naloxone, and was just partially blocked by the $\alpha$-adrenergic antagonist, phentolamine. In the present study, we demonstrated that another non-opioid pain inhibitory pathway, i.e. the cholinergic system, plays a crucial role in mediating the analgesic effect of BV injection on oxaliplatin-induced acute cold allodynia.

Both the nicotinic and muscarinic acetylcholine receptors are located in the deep and superficial dorsal horn of the spinal cord, in which nociceptive information is transmitted and regulated. ${ }^{25-27)}$ In this study, we clearly showed that an i.p. administration of non-selective nicotinic receptor antagonist MEC blocked the anti-allodynic effect of BV treatment in oxaliplatin-injected rats, whereas an injection of muscarinic receptor antagonist ATR did not (Fig. 1). This suggests that BVinduced anti-allodynia in a rat model of oxaliplatin-induced neuropathic pain is mediated by the activation of inhibitory receptors, including nicotinic acetylcholine receptors. Among the pentameric ligand-gated ion channel proteins, two nicotinic receptor subtypes are known to be mainly involved in pain modulation, i.e., the heteromeric $\alpha 4 \beta 2$ and the homomeric $\alpha 7$ receptor. $^{28-30)}$ The $\alpha 7$ nicotinic receptor agonist alleviated an inflammatory pain. ${ }^{31)}$ The $\alpha 4 \beta 2$ nicotinic receptors have been implicated in thermal acute pain $^{32)}$ and the $\alpha 4 \beta 2$ receptors are known to be involved in inhibitory synaptic transmission in the spinal dorsal horn. ${ }^{26,33)}$ The present data indicate that BV treatment activates spinal $\alpha 4 \beta 2$ nicotinic receptors to relieve cold allodynia signs. An i.p. or i.t. injection of selective $\alpha 4 \beta 2$ nicotinic receptor antagonist $\mathrm{DH} \beta \mathrm{E}$ prevented the anti-allodynic effect of $\mathrm{BV}$ injection while an i.p. injection of $\alpha 7$ nicotinic antagonist MLA did not change the BV effect (Figs. 2, 3). These findings are in agreement with prior studies showing that $\alpha 4 \beta 2$ nicotinic acetylcholine receptors mediate spinal antinocieption and anti-allodynia. ${ }^{34,35)}$

It has been reported that acupuncture or EA analgesia is centrally mediated by activation of the descending pain inhibitory system that finally involves spinal opioidergic, noradrenergic and cholinergic receptors. ${ }^{13,27,36)}$ Our previous studies indicate that each of these endogenous analgesic systems substantially contribute to the anti-allodynic effect of EA in peripheral nerve-injured rats. ${ }^{20,37,38)}$ Specifically for the cholinergic mechanism, spinal muscarinic receptors, but not nicotinic receptors, were involved in such EA effect. ${ }^{20)}$ We recently showed that EA significantly reduced acute cold allodynia in oxaliplatin-injected rats via the stimulation of the endogenous opioids, not via the activation of the noradrenergic system. ${ }^{16)}$ In contrast, the present results, together with our previous report, ${ }^{17)}$ indicate that the relieving effect of BV injection on oxaliplatin-induced cold allodynia does not involve the activation of muscarinic acetylcholine receptors and opioid receptors, but involves the activation of nicotinic acetylcholine receptors and/or the partial activation of noradrenergic receptors. We also confirmed that BV injection into a Yaoyangguan acupoint that is proximal to the tail showed a greater analgesic effect than BV injection into Zusanli or Quchi acupoint that is distal to the tail (Supplementary Fig. 1), whereas EA stimulation showed the opposite result (unpublished data). These findings strongly suggest that BV injection and EA stimulation might have distinct mechanisms for their anti-allodynic effects in oxaliplatin-administered rats. However, we cannot completely rule out the other possibility that the expression levels of nicotinic and muscarinic receptors might be different between the oxaliplatin-injected and nerve injured rats, which affects the distinct cholinergic mechanisms of BV- and EAinduced anti-allodynia. Further quantitative studies are needed to address this issue.

In conclusion, we showed that the relieving effect of BV injection on oxaliplatin-induced cold allodynia was blocked by a systemic administration of non-selective nicotinic receptor antagonist, but not by an administration of muscarinic receptor antagonist. Further, the anti-allodynic effect of BV injection was blocked by a systemic or i.t. administration of $\alpha 4 \beta 2$ nicotinic receptor antagonist, but not by an administration of $\alpha 7$ nicotinic antagonist. These results suggest that BV treatment alleviates oxaliplatin-induced neuropathic cold allodynia in rats via the activation of nicotinic acetylcholine receptors, especially spinal $\alpha 4 \beta 2$ receptors. Thus, our findings may provide a useful scientific evidence for the application of subcutaneous injection of diluted BV for the management of neuropathic cold allodynia, a dose-limiting side effect by an oxaliplatin administration in cancer patients.

Acknowledgments This work was supported by the National Research Foundation of Korea (NRF) Grant funded by the Korea Government (NRF-2013R1A1A1012403). We thank Drs. Lee G, Moon HJ, Lim BS, Gil MS, Kim WJ and Go DH for excellent technical supports and discussions on the experiments and manuscript.

Conflict of Interest The authors declare no conflict of interest.

Supplementary Materials The online version of this article contains supplementary materials.

\section{REFERENCES}

1) Alberts SR, Horvath WL, Sternfeld WC, Goldberg RM, Mahoney MR, Dakhil SR, Levitt R, Rowland K, Nair S, Sargent DJ, Donohue JH. Oxaliplatin, fluorouracil, and leucovorin for patients with unresectable liver-only metastases from colorectal cancer: a North Central Cancer Treatment Group phase II study. J. Clin. Oncol., 23, 9243-9249 (2005).

2) Desoize B, Madoulet C. Particular aspects of platinum compounds used at present in cancer treatment. Crit. Rev. Oncol. Hematol., 42 317-325 (2002).

3) Extra JM, Espie M, Calvo F, Ferme C, Mignot L, Marty M. Phase I study of oxaliplatin in patients with advanced cancer. Cancer Chemother. Pharmacol., 25, 299-303 (1990).

4) Gamelin E, Gamelin L, Bossi L, Quasthoff S. Clinical aspects and molecular basis of oxaliplatin neurotoxicity: current management and development of preventive measures. Semin. Oncol., 29 (Suppl. 15), 21-33 (2002).

5) Lehky TJ, Leonard GD, Wilson RH, Grem JL, Floeter MK. Oxaliplatin-induced neurotoxicity: acute hyperexcitability and chronic 
neuropathy. Muscle Nerve, 29, 387-392 (2004).

6) Ling B, Coudore F, Decalonne L, Eschalier A, Authier N. Comparative antiallodynic activity of morphine, pregabalin and lidocaine in a rat model of neuropathic pain produced by one oxaliplatin injection. Neuropharmacology, 55, 724-728 (2008).

7) Zhao M, Isami K, Nakamura S, Shirakawa H, Nakagawa T, Kaneko S. Acute cold hypersensitivity characteristically induced by oxaliplatin is caused by the enhanced responsiveness of TRPA1 in mice. Mol. Pain, 8, 55 (2012).

8) Wolf S, Barton D, Kottschade L, Grothey A, Loprinzi C. Chemotherapy-induced peripheral neuropathy: prevention and treatment strategies. Eur. J. Cancer, 44, 1507-1515 (2008).

9) Lee JD, Park HJ, Chae Y, Lim S. An overview of bee venom acupuncture in the treatment of arthritis. Evid. Based Complement. Alternat. Med., 2, 79-84 (2005).

10) Son DJ, Lee JW, Lee YH, Song HS, Lee CK, Hong JT. Therapeutic application of anti-arthritis, pain-releasing, and anti-cancer effects of bee venom and its constituent compounds. Pharmacol. Ther., 115, 246-270 (2007).

11) Choi MS, Park S, Choi T, Lee G, Haam K-K, Hong M-C, Min B-I, Bae $\mathrm{H}$. Bee venom ameliorates ovalbumin induced allergic asthma via modulating $\mathrm{CD}^{+} \mathrm{CD} 25^{+}$regulatory $\mathrm{T}$ cells in mice. Cytokine, 61, 256-265 (2013).

12) Yoon SY, Yeo JH, Han SD, Bong DJ, Oh B, Roh DH. Diluted bee venom injection reduces ipsilateral mechanical allodynia in oxaliplatin-induced neuropathic mice. Biol. Pharm. Bull., 36, 1787-1793 (2013).

13) Kim W, Kim SK, Min BI. Mechanisms of electroacupuncture-induced analgesia on neuropathic pain in animal model. Evid. Based Complement. Alternat. Med., 2013, 436913 (2013).

14) Baek YH, Huh JE, Lee JD, Choi do Y, Park DS. Antinociceptive effect and the mechanism of bee venom acupuncture (apipuncture) on inflammatory pain in the rat model of collagen-induced arthritis: Mediation by alpha2-adrenoceptors. Brain Res., 1073-1074, 305-310 (2006).

15) Kang SY, Kim CY, Roh DH, Yoon SY, Park JH, Lee HJ, Beitz AJ, Lee JH. Chemical stimulation of the ST36 acupoint reduces both formalin-induced nociceptive behaviors and spinal astrocyte activation via spinal alpha2-adrenoceptors. Brain Res. Bull., 86, 412-421 (2011).

16) Moon HJ, Lim BS, Lee DI, Ye MS, Lee G, Min BI, Bae H, Na HS, Kim SK. Effects of electroacupuncture on oxaliplatin-induced neuropathic cold hypersensitivity in rats. J. Physiol. Sci., 64, 151-156 (2014).

17) Lim BS, Moon HJ, Li DX, Gil M, Min JK, Lee G, Bae H, Kim SK, Min BI. Effect of bee venom acupuncture on oxaliplatin-induced cold allodynia in rats. Evid. Based Complement. Alternat. Med., 2013, 369324 (2013).

18) Bartolini A, Di Cesare Mannelli L, Ghelardini C. Analgesic and antineuropathic drugs acting through central cholinergic mechanisms. Recent Pat. CNS Drug Discov., 6, 119-140 (2011).

19) Eisenach JC. Muscarinic-mediated analgesia. Life Sci., 64, 549-554 (1999).

20) Park JH, Kim SK, Kim HN, Sun B, Koo S, Choi SM, Bae H, Min BI. Spinal cholinergic mechanism of the relieving effects of electroacupuncture on cold and warm allodynia in a rat model of neuropathic pain. J. Physiol. Sci., 59, 291-298 (2009).

21) Zimmermann M. Ethical guidelines for investigations of experimental pain in conscious animals. Pain, 16, 109-110 (1983).

22) Ling B, Coudore-Civiale MA, Balayssac D, Eschalier A, Coudore F, Authier N. Behavioral and immunohistological assessment of pain- ful neuropathy induced by a single oxaliplatin injection in the rat. Toxicology, 234, 176-184 (2007).

23) Yin CS, Jeong HS, Park HJ, Baik Y, Yoon MH, Choi CB, Koh HG. A proposed transpositional acupoint system in a mouse and rat model. Res. Vet. Sci., 84, 159-165 (2008).

24) De la Calle JL, Paino CL. A procedure for direct lumbar puncture in rats. Brain Res. Bull., 59, 245-250 (2002).

25) Coggeshall RE, Carlton SM. Receptor localization in the mammalian dorsal horn and primary afferent neurons. Brain Res. Brain Res. Rev., 24, 28-66 (1997).

26) Takeda D, Nakatsuka T, Gu JG, Yoshida M. The activation of nicotinic acetylcholine receptors enhances the inhibitory synaptic transmission in the deep dorsal horn neurons of the adult rat spinal cord. Mol. Pain, 3, 26 (2007).

27) Millan MJ. Descending control of pain. Prog. Neurobiol., 66, 355474 (2002).

28) Bannon AW, Decker MW, Holladay MW, Curzon P, Donnelly-Roberts D, Puttfarcken PS, Bitner RS, Diaz A, Dickenson AH, Porsolt RD, Williams M, Arneric SP. Broad-spectrum, non-opioid analgesic activity by selective modulation of neuronal nicotinic acetylcholine receptors. Science, 279, 77-81 (1998).

29) Pacini A, Di Cesare Mannelli L, Bonaccini L, Ronzoni S, Bartolini A, Ghelardini C. Protective effect of alpha7 nAChR: behavioural and morphological features on neuropathy. Pain, 150, 542-549 (2010).

30) Khan IM, Buerkle H, Taylor P, Yaksh TL. Nociceptive and antinociceptive responses to intrathecally administered nicotinic agonists. Neuropharmacology, 37, 1515-1525 (1998).

31) Wang Y, Su DM, Wang RH, Liu Y, Wang H. Antinociceptive effects of choline against acute and inflammatory pain. Neuroscience, 132, 49-56 (2005).

32) Jain KK. Modulators of nicotinic acetylcholine receptors as analgesics. Curr. Opin. Investig. Drugs, 5, 76-81 (2004).

33) Rashid MH, Furue H, Yoshimura M, Ueda H. Tonic inhibitory role of alpha4beta2 subtype of nicotinic acetylcholine receptors on nociceptive transmission in the spinal cord in mice. Pain, 125, 125-135 (2006).

34) Zhu CZ, Chin CL, Rustay NR, Zhong C, Mikusa J, Chandran P, Salyers A, Gomez E, Simler G, Lewis LG, Gauvin D, Baker S, Pai M, Tovcimak A, Brown J, Komater V, Fox GB, Decker MW, Jacobson PB, Gopalakrishnan M, Lee CH, Honore P. Potentiation of analgesic efficacy but not side effects: co-administration of an alpha4beta2 neuronal nicotinic acetylcholine receptor agonist and its positive allosteric modulator in experimental models of pain in rats. Biochem. Pharmacol., 82, 967-976 (2011).

35) Lee CH, Zhu C, Malysz J, Campbell T, Shaughnessy T, Honore P, Polakowski J, Gopalakrishnan M. Alpha4beta2 neuronal nicotinic receptor positive allosteric modulation: an approach for improving the therapeutic index of alpha4beta 2 AChR agonists in pain. Biochem. Pharmacol., 82, 959-966 (2011).

36) Ossipov MH, Morimura K, Porreca F. Descending pain modulation and chronification of pain. Curr. Opin. Support. Palliat. Care, 8, 143-151 (2014).

37) Kim JH, Min BI, Na HS, Park DS. Relieving effects of electroacupuncture on mechanical allodynia in neuropathic pain model of inferior caudal trunk injury in rat: mediation by spinal opioid receptors. Brain Res., 998, 230-236 (2004).

38) Kim SK, Park JH, Bae SJ, Kim JH, Hwang BG, Min BI, Park DS, $\mathrm{Na}$ HS. Effects of electroacupuncture on cold allodynia in a rat model of neuropathic pain: mediation by spinal adrenergic and serotonergic receptors. Exp. Neurol., 195, 430-436 (2005). 